\title{
IMPLEMENTASI NILAI-NILAI FALSAFAH OJO DUMEH DIKALANGAN MAHASISWA UNIVERSITAS BINA NUSANTARA
}

\author{
Besar \\ Jurusan Psikologi, Fakultas Psikologi, Bina Nusantara University \\ Jln. Kemanggisan Ilir III No 45, Kemanggisan, Palmerah, Jakarta Barat 11480 \\ besar@binus.edu
}

\begin{abstract}
Ojo Dumeh is the old philosophy that comes from Javanese language that has meaning do not being arrogant. If the value of this philosophy is implemented, it will have incredible power because old values never fade. The three main pillars of this are Ojo Dumeh, Ojo Gumunan, Ojo Kagetan; each of which has implemented power. The message is always delivered by parents to their children from childhood with the intention that their children do not become someone who are arrogant and always appreciate a friend or someone else. Research at BINUS University students are to learn about the importance of Ojo Dumeh in everyday life among students and to know more deeply about the relationship between philosophies Ojo Dumeh with changes in student behavior. The methodology of the research is exploratory, data used are primary data and secondary data obtained from the first source of BINUS University students, and the data obtained from the teaching philosophies that are books and literature. Based on the research, it can be concluded that the Ojo Dumeh philosophy needs to be implemented in the lives of students and believe that by applying this philosophy Ojo Dumeh the relationship will be better.
\end{abstract}

Keywords: ojo dumeh, values, overcome attitudes

\begin{abstract}
ABSTRAK
Ojo dumeh adalah Falsafah lama yang berasal dari bahasa Jawa yang memiliki arti jangan mentangmentang. Apabila nilai-nilai falsafah ini diimplementasikan, maka akan mempunyai kekuatan yang sangat luar biasa karena nilai-nilai lama tidak pernah pudar. Tiga pilar utama dari falsafah ini adalah Ojo Dumeh, Ojo Gumunan, Ojo Kagetan, yang masing-masing mempunyai daya implementatif. Pesan yang selalu disampaikan oleh orang tua kepada anaknya sejak kecil hingga dewasa ini dengan maksud agar anaknya tidak menjadi orang yang suka mentang-mentang dan selalu menghargai teman atau orang lain. Penelitian pada mahasiswa BINUS University ini untuk mengetahui mengenai pentingnya Ojo Dumeh dalam kehidupan sehari-hari di kalangan mahasiswa serta untuk mengetahui lebih mendalam mengenai hubungan antara falsafah Ojo Dumeh dengan perubahan perilaku mahasiswa. Metodologi penelitian yang digunakan adalah eksploratoris, Data yang digunakan adalah data primer dan data skunder yang diperoleh dari sumber pertama yakni dari mahasiswa BINUS University dan data yang diperoleh dari falsafah yang ada dalam buku dan literatur. Berdasarkan hasil penelitian, maka dapat disimpulkan bahwa Falsafah Ojo Dumeh perlu diimplementasikan di dalam kehidupan mahasiswa dan meyakini bahwa dengan menerapkan falsafah Ojo Dumeh ini, maka hubungan dengan sesama akan lebih baik.
\end{abstract}

Kata kunci: ojo dumeh, nilai-nilai, mengatasi sikap 


\section{PENDAHULUAN}

\section{Pengertian}

Pengertian Ojo dumeh yang dalam bahasa sekarang mungkin bisa diterjemahkan langsung sebagai jangan mentang-mentang atau jangan sok ini dianggap filosofi yang aplikatif sepanjang masa dan sangat powerful. Ajaran Ojo Dumeh menyarankan kepada kita agar jangan sampai kelebihan ataupun kehebatan yang kita miliki justru menjadi bumerang, membunuh diri sendiri. Kelebihan seseorang bisa dalam bentuk kekayaan, keahlian, jabatan, ketampanan atau kecantikan, kepopuleran, ataupun keturunan. Ojo Dumeh adalah salah satu ajaran dasar leluhur kita untuk selalu melakukan introspeksi diri terhadap lingkungan, sesama manusia, dan juga kepada Sang Pencipta.

Ojo Dumeh adalah Falsafah kuno, dari bahasa Jawa yang memiliki arti Ojo = jangan, dan Dumeh = sombong, pamer, lupa diri.ketika seseorang sudah dihinggapi Ojo Dumeh. Falsafah jawa Ojo Dumeh merupakan salah satu dari tiga falasafah jawa-Ojo Gumunan, Ojo Kagetan, dan Ojo Dumeh-yang biasanya menjadi falsafah kehidupan yang utama bagi masyarakat jawa mulai dari kanak-kanak sampai masa tuanya. Ada sebagian pendapat yang mengatakan bahwa ajaran ini merupakan Ideologi Gado-Gado Marhaenisme Soekarno, Vatikan \& Khilafah Utsmani, namun falsafah ini lebih kepada bentuk sinkretisme teologi (ajaran) Islam, Hindu-Budha dan Jawa.

Masyarakat Indonesia khususnya masyarakat jawa, telah dikenalkan falsafah ini sejak kecil, setelah mereka mengenal lingkngan. Biasanya, orang tua akan selalu me-wanti-wanti (berpesan dengan sungguh-sungguh) kepada anak ketika akan keluar rumah dan bermain dengan teman sepermainannya dengan kata-kata "ojo dumeh". Maksud si orang tua antara lain agar anaknya tidak mentang-mentang terhadap teman sepermainan, dan selalu menghargai teman atau orang lain. Ketika anak menginjak dewasa, kata-kata (falsafah) itu juga akan selalu disampaikan, sampai anak berumah tangga dan ketika anaknya akan memasuki dunia kerja sekalipun.

\section{Keseimbangan dalam Ojo Dumeh}

Keseimbangan dalam ojo dumeh yang sering kita dengar adalah kalimat "koyo ngono yo koyo ngono ning ojo koyo ngono" yang diartikan secara bebas adalah "begitu ya begitu tapi jangan begitu“. Kandungan makna dari kata kata tersebut adalah kita boleh saja menjadi apa yang kita inginkan tapi kita harus selalu ingat. Harus ada keseimbangan antara apa yang kita telah sandang dengan sebagai penghormatan diri dengan penghormatan terhadap orang lain. Keseimbangan dalam ojo dumeh akan menghasilkan komunikasi yang baik, menghargai dan menghormati orang lain, tidak menaruh prasangka, meningkatkan rasa kepedulian terhadap sesama.

Lalu, apa yang diinginkan oleh falsafah Ojo Dumeh ini? Setidaknya, ada dua hal yang dapat kita ambil dari Ojo Dumeh, yaitu (1) Ojo Dumeh sebagai falsafah, maka Ojo Dumeh adalah nilai yang telah digali dari akarnya budaya yang mendalam, yang mempunyai makna apabila dijalankan maka kehidupan masyarakat akan berjalan dengan tertib; (2) Ojo Dumeh sebagai nilai etis, maka yang dimunculkan dan dikedepankan adalah nilai baik dan buruk. Sebagai contoh: Mentang-mentang sebagai mahasiswa kemudian tidak mau berbaur dengan para petani atau mentang-mentang menjadi polisi kemudian berlaku seenaknya terhadap yang lain. Posisi yana dia secara individu adalah baik. Sebagai mahasiswa adalah baik, sebagai polisi adalah baik, yang tidak baik adalah perlakuan seenaknya terhadap yang lain, sifat tidak mau berbaurnya itu yang tidak baik

Ojo Dumeh adalah bagian dari upaya untuk mengesampingkan segenap keinginan pribadi. Orang yang menerapkan falsafah Ojo Dumeh akan senantiasa menganggap orang lain pada posisi yang sangat manusiawi. Orang yang menerapkan falsafah Ojo Dumeh tidak akan mengorbankan orang 
lain demi kepentingannya sendiri atau demi mempertahankan kepemimpinannya dirinya sendiri seperti Nero dan Caligula atau juga Raja Inggris sir John yang dinilai takbermoral yang hanya memikirkan dirinya sendiri, atau bukan juga orang atau pemimpin yang mengorbankan dirinya untuk orang lain seperti yang dilakukan oleh Sir Phipip Sidney dari inggris yang membiarkan dirinya tewas kehabisan darah dalam suatui pertempuran dan bahkan dia memberikan sebotol air yang ada pada dirinya kepada seorang prajurit (Walters 2004).

Berbeda dengan Ojo Dumeh, adalah kalimat Sabdo Pandito Ratu. Ojo Dumeh adalah falsafah atau wisdom yakni nilai-nilai yang hidup di masyarakat dan menjadi pedoman dalam kehidupan sehari-hari orang jawa sedangkan Sabdo Pandito Ratu adalah semacam petuah atau- kata-kata yang biasanya harus dituruti oleh warganya atau umatnya. Sabdo yang berarti Kata atau Perkataan atau Patuwuh atau Petuah yang biasanya diucapkan oleh Pemimpin negara atau pemimpin keagamaan atau tokoh masyarakat. Sabdo Pandito Ratu ini biasanya suaranya didengar, atau kalau itu adalah petunjuk maka petunjuknya itu akan diikuti, perilakunya ditiru (Bhikkhu Dhammasubho, 2009).

\section{Tujuan}

Tujuan yang ingin dicapai dalam penelitian ini adalah untuk mengetahui mengenai pentingnya Ojo Dumeh dalam kehidupan sehari-hari dikalangan mahasiswa serta untuk mengetahui lebih mendalam mengenai hubungan antara Falsafah Ojo Dumeh dengan perubahan perilaku mahasiswa.

\section{Manfaat}

Manfaat yang diharapkan dari penelitian ini adalah membantu pihak kampus dalam menghasilkan informasi yang akurat, relevan efektif dan efisien sehubungan dengan pengembangan materi ajar, sehingga dapat digunakan untuk menambah muatan materi ajar pada mata kuliah Character Building.

\section{METODE PENELITIAN}

Dalam penelitian menggunakan tipe penelitian deskriptif. Penulisan ini juga menggunakan tipe empiris dan komparatif. Data yang dibutuhkan diperoleh dari mahasiswa BINUS University sebagai data primer dan dari ajaran atau falsafah yang ada dalam buku-buku dan literatur-literatur sebagai data skunder. Teknik pengumpulan data adalah dengan studi kepustakaan yaitu mengumpulkan data dengan cara mempelajari buku-buku sebagai bahan acuan serta hasil karya tulis lainnya, sebagai pembuatan kerangka teori mengenai masalah yang menjadi obyek penelitian dan wawancara yaitu pengumpulan data dengan cara mengadakan wawancara bebas dan tidak bersistem dan dengan mengajukan pertanyaan-pertanyaan yang telah dipersiapkan pada saat pertemuan. Cara Pengolahan Data adalah dengan cara diolah secara kualitatif, yaitu pengolahan data hasil masukan dari responden secara tertulis atau secara lisan (dengan menggunakan metode wawancara atau kuesioner) kemudian dikualifikasikan guna memperoleh kesimpulan yang utuh. Lokasi Penelitian ini dilaksanakan BINUS University, Jakarta.

\section{HASIL DAN PEMBAHASAN}

Penelitian dilaksanakan pada beberapa mahasiswa yang mengambil kelas Character Building khususnya Character Building 2, Relasi dengan Sesama, dengan jurusan yang berbeda di BINUS University. Untuk dua semester yang terdiri 13 kali pertemuan, mahasiswa diberikan tugas-tugas oleh dosen untuk membuat catatan-catatan kecil dan final project baik individu maupun kelompok. Catatan-catatan kecil tersebut dikerjakan secara sendiri tanpa ada campur tangan dari dosen, dan final 
project dikerjakan secara tidak beraturan, dengan melalui penugasan individu dan dengan penugasan kelompok yang terdiri antara 7 sampai 10 orang.

Dengan mengesampingkan pengukuran dengan pendekatan Indeks Prestasi Kumulatif mahasiswa yang ada pada tiap-tiap kelas, didapat sebaran sebagai berikut:

Tabel 1

\begin{tabular}{ccccc}
\hline Tahun & Jum Mhs & Jum yg Mengump Tugas & Jum yg Setuju & Jum yg tdk Setuju \\
\hline $2009(1)$ & 117 & 108 & 100 & 8 \\
$2009(2)$ & 162 & 157 & 132 & 25 \\
\hline
\end{tabular}

Dari data diatas dapat dilihat bahwa mahasiswa ganjil yang mengumpulkan tugas dan berpendapat bahwa falsafah ojo dumeh itu bisa diimplementasikan adalah sebesar $93 \%$ dan yang tidak sependapat adalah $7 \%$. Pada semester genap mahasiswa yang berpendapat bahwa ojo dumeh bisa diimplementasikan adalah 84\%, sedangkan sisanya adalah sebanyak $16 \%$ ini tidak semuanya menyatakan tidak sependapat akan tetapi 15 atau 9,5\% mahasiswa tidak sependapat karena beralasan tidak memahami sama sekali. Sementara sisanya 10 mahasiswa atau 6,5 \% tikda sependapat karena mengetahui bahwa ojo dumeh adalah suatu ajaran atau falsafah yang dianggapnya cengeng dan munafik.

Ojo Dumeh yang kita megetahuinya hanya sebagai kata yang dipadankan dengan jangan mentang-mentang saja ternyata kalai diteliti secara mendalam akan mengenai segala segi perilaku kehidupan manusia. Dengan tiga pilar utama "ojo" ini yakni "ojo dumeh", "ojo gumunan”, “ojo kagetan" muncul serangkaian ojo-ojo lainnya yang mengena kepada siapa saja dan dimana saja, sebagai contoh ojo dumeh adalah:

- Dumeh kowe kuwasa trus biso 'ngidek-idek' sedulurmu sakepenake? (Mentang-mentang kamu berkuasa terus bisa 'menginjak-injak' saudaramu dengan seenaknya?)

- Dumeh kowe sugih trus biso sia-sia marang sedulurmu kang ora duwe? (Mentang-mentang kamu kaya terus bisa menyia-nyiakan saudaramu yang tidak berpunya?)

- Dumeh kowe pinter trus biso sakepenake nggunakake kapinteranmu kuwi kanggo 'minteri' wong-wong sing ora ngerti apa-apa? (Mentang-mentang kamu pandai terus bisa menggunakan kepandaianmu itu untuk membodohi orang lain yang tidak mengerti apa-apa?)

- Dumeh kowe luwih ngerti trus biso 'petantang-petenteng' lan nganggep wong liya ora ana ajine opo-opo? (Mentang-mentang kamu lebih mengerti terus bisa tolak pinggang setinggi dada dan mengganggap orang lain tidak ada harganya di depanmu?)

- Dumeh kowe luwih 'cedhak karo gusti' trus ngganggep wong liya murtad? (Mentang-mentang kamu lebih dekat dengan Tuhan terus menganggap orang lain murtad?)

- Amergo opo sing kokduweni saiki kuwi kabeh asale soko Gusti. (Karena apa yang kamu punyai saat ini semua berasal dari Tuhan.)

Contoh ojo gumunan adalah:

Bangsa yang suka gumunan artinya mudah terheran-heran. Terheran-heran dengan produkproduk mobil dari Jepang yang memiliki fitur-fitur berteknologi canggih, terheran-heran dengan teknologi hand, terheran-heran dengan produk seluler terbaru yang bernama BlackBerry sehingga hampir semua penduduk Indonesia saat ini berduyun-duyun dan cenderung bertindak latah. Kita diombang-ambingkan oleh rasa gumunan terhadap sesuatu yang baru dan tidak pernah tersadar bahwa kita menjadi mangsa empuk para pemasar kolonialis dari luar. (Suprayogi, 2010) 
Contoh dari ojo kagetan adalah:

Bangsa kita suka kagetan yang artinya mudah terkejut. Terkejut kok dapat hutang banyak dari IMF \& World Bank di awal kekuasaan Orde Baru; terkejut kok dapat duduk sebagai wakil rakyat; terkejut kok dapat posisi sebagai Bupati; terkejut kok bisa duduk sebagai menteri; terkejut kok Malaysia sekarang sudah sedemikian maju meninggalkan kita; terkejut kok Cina banyak sekali mengekspor produk-produk murah dengan begitu massive-nya ke Indonesia; terkejut kok hampir semua lapak penjual buah di pinggir-pinggir jalan berisi buah-buahan impor dari Thailand; terkejut kok sudah ratusan juta kendaraan motor berlalu lalang di jalanjalan di Indonesia tapi tidak ada satupun yang berlogo made in Indonesia; terkejut kok Tambang Freeport ternyata banyak mengandung emas dan uranium, dan beragam keterkejutan lainnya. (Suprayogi, 2010)

Dari hasil pengumpulan tugas mahasiswa, mereka menyatakan pendapatnya bahwa Ojo Dumeh itu bisa diimplementasikan dengan anggapan bahwa (1) Ojo Dumeh itu adalah nilai yang baik dan tidak ada ajaran yang mempunyai filosofi yang tinggi mengajarkan yang tidak baik; (2) Ojo Dumeh bisa diimplementasikan karena ojo dumeh adalah menganding nilai yang sangat luhur yang diyakininya sangat bisa mendamaikan mahasiswa, masyarakat, bangsa, negara bahkan dunia, jika memang betul-betul diterapkan.

Sebagai contoh bahwa Ojo Dumeh mengandung nilai yang luhur dan bisa mendamaikan antara orang yang satu dengan yang lain adalah: Ojo Dumeh kowe kuwasa trus biso 'ngidek-idek' sedulurmu sakepenake! Artinya: Jangan Mentang-mentang kamu berkuasa terus bisa 'menginjakinjak' saudaramu dengan seenaknya! Banyak yang bisa kita ambil pada kehidupan sehari-hari, seperti (1) mentang-mentang orang tua, seenaknya bentak-bentak anaknya, mentang-mentang anak seenaknya membangkang perintah orang tua; (2) mentang-mentang tukang becak, seenaknya menerobos sana sisi tanpa memperhatikan rambu-rambu lalu lintas; (3) mentang-mentang penumpang seenaknya menyetop kendaraan disembarang tempat yang dapat mengganggu jalur lalu lintas; (4) mentang-mentang tenaga pengajar bisanya cuma memanfaatkan kesempatan dan kesempitan terhadap anak muridnya; (5) mentang-mentang pejabat, memanfaatkan jabatannya untuk memindahkan uang dari saku kantor ke saku pribadinya; (6) mentang-mentang rakyat kecil berlaku seenaknya tanpa memperdulikan orang lain dengan alasan faktor ekonomi.

Selain itu, (3) bahwa ojo dumeh walaupun berasal dari bahasa dan kebiasaan jawa, kalau disosialisasikan secara benar dan terus menerus dan dengan memberikan arti yang tepat maka akan bisa diterima disemua lapisan masyarakat. Alasan bahwa nilai-nilai atau falsafah jawa ini kalau disosialisasikan dengan benar dan dijalankan dengan benar bisa diterima oleh semua lapisan masyarakat adalah bahwa bangsa Indonesia ini sangat beragam dan sebagian besar adalah suku jawa, hampir semua orang telah mengenal jawa dan berinteraksi dengan suku jawa, Sebagai contoh bahwa falsafah ini bisa diterima adalah sebagai berikut: Pengusaha tionghoa dia fasih betul dalam mengungkapkan dan menginterpretasikan tentang Javaness wisdom (kearifan atau petuah bijak orang Jawa). Dia termasuk pengusaha Tionghoa sukses di bidangnya dan telah memiliki karyawan sampai dengan 1000-an orang. Dalam percakapan bebas dengan orang jawa sebagai berikut:

“Mas, saya lahir di Indonesia, besar di Indonesia, makan minum dan cari uang di Indonesia, menikah dan membesarkan anak-anak saya di Indonesia, dan saya tinggal di tanah jawa, bahkan dari kecilpun saya sudah fasih berbahasa Jawa, pembantu-karyawan- dan orang-orang kepercayaan saya dalam perusahaan saya adalah orang-orang jawa, jadi saya paham betul kearifan yang ada di budaya orang jawa”. Ojo Dumeh, Ojo Kagetan, ojo Gumunan itu kearifan yang bagus sekali mas buat kita, tapi sayangnya orang jawa khususnya dan orang Indonesia pada umumnya tidak atau jarang yang mau menjalankannya. Kalau saya sendiri sudah berusaha mempraktekannya sejak dulu.” (Suprayogi, 2010) 
Ojo Dumeh juga (4) dapat selalu mengingatkan agar kita sebagai mahasiswa agar senantiasa sadar diri. Sadar diri ini menciptakan sifat kehati-hatian, dengan selalu ingat pada adanya orang disekitar kita atau orang yang berada di bawah kita, dan memberikan isyarat bahwa kalau kita tidak berhati-hati maka kita bisa jatuh ke posisi tersebut. Ojo Dumeh menciptakan sifat kehati-hatian bukan menciptakan kekhawatiran atau sifat takut. Misalnya, Ojo Dumeh (Jangan mentang-mentang), Jangan mentang-mentang kita sedang berkuasa terus berbuat seenaknya dan membabi buta. Ada hukum sebab akibat, ada aksi ada reaksi; (2) Ojo sok Dumeh (Jangan sok mentang-mentang), Hidup janganlah suka dibuat-buat. Kalau kita tidak berkuasa maka jangan kuta sok berkuasa dan jangan pura-pura berkuasa; (3) Ojo kepengen Dumeh (Jangan punya keinginan mentang-mentang), Prinsip yang harus menjadi pegangan adalah jangan kita berusaha untuk menjadi orang yang mentangmentang. Jangan kita berupaya untuk menjadi orang yang sok berkuasa dengan menghalalkan segala cara.

Selain itu, (5) berkaitan dengan hubungan dengan sesama Ojo Dumeh akan membuat mahasiswa atau orang lain senang. Mahasiswa atau orang lain senang karena kita tidak mentangmentang, tidak merendahkan mereka. Saat kita menyenangkan mahasiswa atau orang lain, orangorang tersebut akan senang berada di sekitar kita. Mereka tidak ingin kita jauh dari mereka. Apa lagi lepas dari mereka, mereka akan menjaga kita untuk stay in our position. Mereka ingin kita ada disekitar mereka dan berharap agar kita juga bisa lebih baik pisisi atau status sosialnya. Pada posisi yang seperti sekarang ini saja kita bisa menyenangkan mereka, sehingga pada saat kita berhasil berada di posisi yang lebih tinggi mereka berharap bahwa kita akan lebih menyenangkan mereka. Sebagian dari mahasiswa yang lain beralasan bahwa ojo dumeh adalah perlu, mereka berpendapat bahwa menyenangkan orang lain pada adalah prinsipnya ibadah. Sebagai contoh

Sebagai contoh, apabila ada mahasiswa yang kuliah dengan berangkat dan berbekal dengan prinsip falsafah Ojo Dumeh, dia kuliah dengan semangat dan sungguh-sungguh untuk mendapat ilmu dan nilai yang tinggi, kemudian dia bisa mendapatkan apa yang dia inginkan yakni ilmu atau nilai yang tinggi. Pada posisi yang demikian dia sebagai mahasiswa tetap rendah hati, dia tetap menghargai pendapat orang lain walaupun dengan orang yang lebih rendah (bodoh) dari dia. Dia tidak mentangmentang mempunyai ilmu atau nilainya yang dia miliki. Dia tidak mentang-mentang dengan prestasi tinggi dan lupa membagi ilmu kepada yang lain. Dia tetap menimba ilmu dan mendengarkan dari teman kuliah yang lain termasuk dari teman mahasiswa yang lebih rendah (bodoh) dari dia dan seperti apapun kekurangan mereka. Dia tetap belajar dan semakin banyak membagi ilmu kepada mahasiswa yang lain. Dalam kondisi seperti ini apakah kita akan benci kepada mahasiswa tersebut? Tentu kita akan berfikir dua kali kalau kita mau merasa tidak senang kepada mahasiswa tersebut dan tidak ada alasan untuk tidak senang apalagi mahasiswa tersebut aktif berorganisasi dan suka membantu kepada sesama

Contoh lain adalah apabila ada seorang pekerja yang bekerja dengan berbekal dengan prinsip falsafah ojo dumeh, pekerja tersebut bekerja keras untuk menciptakan kinerja yang ditargetkan, kemudian dia bisa mendapatkan apa yang dia inginkan posisi yang tinggi. Pada posisi yang demikian dia sebagai karyawan, tetap rendah hati, dia tetap menghargai pendapat orang lain walau posisinya lebih rendah dari pekerja tersebut. Dia tidak mentang-mentang mempunyai kekuasaan kemudian berbuta semena-mena dengan kekuasaannya. Dia tidak mentang-mentang berpenghasilan tinggi kemudian membelanjakan uang dia semau dia sampai lupa berderma. Dia tetap mendengarkan teman kerjanya dari semua level jabatan. Dia tetap hemat dan semakin banyak berderma. Bagaimana dengan profil karyawan seperti itu? Apakah kita ingin orang tersebut turun jabatan atau pindah jabatan atau pindah tugas atau bahkan kita berkeinginan agar pekerja tersebut diberhentikan dari tempat kerjanya yang sekarang? Tentunya tidak, kita akan merasa senang dengan kehadiran orang seperti itu. Kita tidak melihat orang tersebut berasal dari mana, dan mempunyai perilaku diluar kerja yang bagaimana.

(6) Ojo dumeh ini untuk dan bisa menunjukkan bahwa sebetulnya kita adalah orang yang senantiasa bersyukur. Dengan kita tidak 'mentang-mentang' berarti kita menyatakan pada diri kita 
sendiri bahwa apa yang ada pada kita yang sekarang ini (semua predikat yang melekat pada kita) cukup untuk kita dan wajib kita syukuri. Kalau kita diberi lebih dari yang sekarang ini tentunya kita akan lebih bersyukur lagi.

(7) Ojo dumeh dapat membuat kita berhemat tenaga dan fikiran. Sebagai contoh adalah kalau kita senantiasa merendahkan orang lain atau mengumpat orang lain atau berfikir negatif tentang orang lain itu hanya akan menguras tenaga dan fikiran kita. Kita lebih baik mensyukuri apa yang ada pada kita dan membiarkan apa yang ada pada orang lain sebagai sesuatu yang wajar dan memang sudah menjadi haknya. Perbedaan apa yang kita miliki atau perbedaan apa yang melekat pada diri kita adalah dipengaruhi oleh apa yang kita usahakan dan diantaranya adalah apa yang telah diberikan oleh Tuhan kepada kita. Prinsip yang bisa dipegang adalah "setiap orang pasti diberikan kelebihan dan kekurangan masing-masing oleh Tuhannya. Sehingga apa yang ada pada kita kita syukuri dan apa yang ada pada orang lain biarkan itu melekat pada orang lain. Kita harus senantiasa mnempatkan segala sesuatu pada porsinya saja. Berfikir positif seperti ini akan menghemat energi kita. Apalagi orang yang merasa kita hargai tersebut juga kemudian menghargai kita, hal tersebut justru akan me-recharge energi kita.

(8) Ojo Dumeh merupakan pengendalian diri. Yang dimaksud pengendalian diri disini adalah mendorong dan membawa diri kita kepada keadaan yang kita inginkan dan menahan diri kita sendiri untuk tidak mengambil tindakan atau menuruti keinginan yang sekiranya akan mencelakakan atau menghancurkan kita. Ojo Dumeh akan selalu mengingatkan kita bahwa ternyata disekitar kita banyak sekali hal-hal yang berbeda dengan kita dimana perbedaan tersebut bukannya sesuatu yang kita inginkan. Saat kita diberi kelebihan dalam hal kekayaan misalnya, kita akan melihat bahwa di sekitar kita masih banyak orang yang tidak seberuntung kita. Selama kita menyadari hal tersebut, dan kemudian tidak mengecilkan orang-orang yang kurang beruntung, maka kita justru akan diarahkan oleh keadaan untuk lebih baik dari keadaan kita sekarang dan terhindar dari keadaan yang tidak kita inginkan. Kalau kita mengecilkan orang lain, atau menghina, hal tersebut sama saja dengan kita menyamakan posisi kita seperti posisi mereka. Demikian pula saat berhadapan dengan orang-orang yang tidak seberuntung kita. Kalau kita merendahkan mereka juga sama saja kita downgrade, sama saja dengan mereka. Yang benar adalah saat kita lebih beruntung kita membantu dan mengangkat orang yang kurang beruntung tersebut ke posisi yang lebih baik. Kita boleh merendah, tetapi jangan merendahkan. Ojo dumeh juga sebagai pengendali diri agar kita bisa menahan apa yang kita inginkan tetapi kita setidak-tidaknya patut menduga bahwa hal itu akan berakibat tidak baik untuk kita maka kita menahan diri kita untuk tidak melakukan hal tersebut.

(9) Ojo Dumeh menjadikan kita tidak over valued terhadap diri sendiri. Kalau kita mentangmentang, dan keadaan membiarkan kita terbuai dengan ke“mentang-mentang”an kita, maka kita bisa lupa diri. Sebagai contoh, mentang-mentang kita pandai kemudian kita membodohi orang lain. Orang lain mungkin diam. Kita yang sedang membodohi rasanya tiba-tiba menjadi lebih pandai, melayang tinggi lebih pandai lagi. Itu perasaan yang menipu. Kita justru akan tertipu oleh "mentang-mentang” kita.. Hati-hati, kita bisa over valued terhadap diri sendiri, yang apa bila kita tidak kuat bertahan, hal tersebut justru akan berbalik menjadi menurunkan value kita.

\section{Nilai-Nilai Ojo Dumeh}

\section{Nilai Jujur dan Adil}

Manusia diciptakan dengan konsekuesi melalui tiga proses, yaitu perasaan selalu merasa tidak puas, sifat egois dan mentang-mentang. Tidak mudah merefleksikan falsafah "ojo dumeh" dalam kehidupan, banyak hal yang sering mengakibatkan selalu akan berbuat dan berlaku mentang-mentang. Dengan diawali rasa tidak puas yang diikuti oleh sifat egois dan dengan prilaku yang mentangmentang maka rusaklah diri manusia itu. Beberapa masalah yang timbul pada masyarakat karena disebabkan oleh tindakan yang mentang-mentang. Rusaknya sistem pemerintahan termasuk hilangnya kepercayaan rakyatnya kepada pemegang pemerintahan adalah karena faktor mentang-mentang. 
Dalam kondisi yang demikian maka para pemimpin lebih sering dalam pengambilan keputusan tidak didasarkan oleh keadilan dan kejujuran. Jujur dan Adil adalah dua hal penting agar kepemimpinannya diakui secara positif.

Jujur dan adil memang tidak mudah, tapi harus. Pada saat pemimpin mampu berbuat jujur dan adil maka akan hilanglah sifat mentang-mentang. Sifat mentang-mentang ini sering terjadi ketika orang tidak mampu merefleksikan gaya kepemimpinan yang baik.

\section{Nilai Tata Krama atau Aturan}

Orang Jawa memegang tata krama dalam bertindak, yakni sikap atau perilaku tepat atau etiket. Yang dimaksud adalah keseluruhan peraturan hidup yang diterima secara umum di antara berbagai lapisan sosial, yang masing-masing pihak mempunyai hak dan kewajiban satu sama lain dan terhadap lingkungannya. Kewajiban-kewajiban itu harus dilaksanakan, jika seseorang tidak mau kehilangan kehormatan dan bantuan. Tata artinya aturan hidup masyarakat desa, dan krama artinya aturan hidup priayi di lingkungan keraton. Siapapun harus patuh pada tata dan krama yang selama bertahun-tahun dan turun temurun disepakati oleh seluruh warga. Tata dan krama tidak saja dalam beperilaku dan berhubungan dengan sesama warga, melainkan juga tata aturan membangun rumah. Bentuknya seperti apa, ukurannya berapa, disesuaikan dengan kedudukan sosialnya: siapa yang mengerjakannya, menghadap ke mana, bahan bangunan diperoleh dari mana, dan kapan membangunnya dan lain sebagainya harus sesuai dengan tatakrama yang ada.

Jika seseorang melanggar aturan itu, misalnya, rumahnya bergaya modern, yang mengerjakan bukan warga desa itu, bahan bangunan diperoleh dari luar daerah, menghadapnya berbeda dengan rumah-rumah yang lain, maka dia tidak akan memperoleh penghormatan warga sebagaimana mestinya. Orang hanya akan menghormatinya secara lahiriah saja. Bagi warga, orang yang telah melanggar tata aturan tersebut disebut sebagai "orang kaya baru”. Orang akan berkata Ojo Semugih atau Dumeh Sugih. Kendati dia asli warga itu, orang demikian, dalam sosiologi, disebut sebagai $a$ stranger in the crowd, orang asing di tengah keramaian. Coba bayangkan betapa susahnya jika kita terasing dari lingkungan di mana kita tinggal. Di tengah keramaian yang mestinya kita menikmati suasana ramai, kita justru merasa kesepian karena tidak ada orang yang menyapa. Oleh karena itu, agar kita tidak menjadi orang asing di tengah keramaian (Rahardjo, 2010).

\section{Nilai Etis}

Sebagai anak buah, sifat mentang-mentang itupun bisa terjadi, biasanya timbul tidak kooperatif terhadap pimpinannya, lebih banyak mengandalkan egoisme, pingin berkuasa, suka menyalahkan atasannya, merasa kerjanya cepat, pemahaman lebih, lebih pintar dan suka mengerjakan yang bukan pekerjaannya. Dalam falsafah jawa di kenal: Kena cepet ning aja ndhisiki, kena pinter ning aja ngguroni, kena takon ning aja ngrusuhi. Dari kalimat diatas mencerminkan bahwa nilai sopan santun hendaknya dipegang teguh dengan tidak menghentikan prestasi dan karir seseorang.

\section{Nilai Egaliter}

Sebagai anak buah, biasanya sifat mentang-mentang itu timbul untuk menunjukan bahwa dia lebih bisa dari atasannya, biasanya timbul tidak kooperatif terhadap pimpinannya, lebih banyak mengandalkan egoisme, pingin berkuasa, suka menyalahkan atasannya, merasa kerjanya cepat, pemahaman lebih, lebih pintar dan suka mengerjakan yang bukan pekerjaannya dalam falsafah jawa dikenal : Kena cepet ning aja ndhisiki, kena pinter ning aja ngguroni, kena takon ning aja ngrusuhi yang artinya adalah boleh cepat tapi jangan mendahului, boleh pintar tapi jangan menggurui, boleh tanya tapi jangan merusak suasana. Ojo Dumeh mengajarkan kepada kita bahwa kita semua adalah sama derajatnya, sama-sama mempunyai hak yang sama. 


\section{Nilai Keseimbangan}

Dalam Islam, seseorang yang ingin memiliki ilmu pengetahuan, maka harus dapat mengaplikasikan dan merefleksikan kehidupannya antara ilmu dan iman. Orang yang memiliki ilmu namun tidak beriman, maka akan celaka di akhirat, begitu juga orang yang beriman namun tidak berilmu niscaya akan sengsara hidupnya di dunia. Iman dan ilmu, harus dimiliki oleh manusia secara seimbang. Manusia yang tak seimbang akan mengalami pribadi yang pecah (split personality), yang mengakibatkan orang tersebut akan senantiasa mentang-mentang terhadap orang lain dan akan membahayakan bagi keselamatan lingkungan. Oleh karena itu, perlu diusahakan setiap orang adalah iman dan ilmunya berinteraksi secara seimbang in dynamic equilibrium. Keseimbangan dalam ojo dumeh yang sering kita dengar adalah kalimat koyo ngono yo koyo ngono ning ojo koyo ngono yang diartikan secara bebas adalah begitu ya begitu tapi jangan begitu.

\section{Bagaimana Mengatasi Sikap Mentang-Mentang?}

Mentang-mentang dapat dianggap sebagai perilaku menyimpang dari seseorang di luar standar individu normal, nilai sosial dan kelembagaan. Artinya ada upaya eksploitasi seseorang dengan kedudukannya agar lingkungan mau menerima sikapnya. Intinya orang bersangkutan melakukan legitimasi sendiri tentang perilaku mentang-mentang tersebut tanpa mempertimbangkan kaidah-kaidah yang berlaku umum (Mangkuprawira, 2009).

Sikap mentang-mentang biasanya menempel pada seseorang status social maupun ekonominya lebih tinggi. Orang yang status sosial atau ststus ekonominya rendah biasanya jarang berperilaku mentang-mentang. Sikap mentang-mentang yang sering kita temui antara lain adalah (1) mentang-mentang dosen mengamnggap mahasiswa bimbingannya bodoh; (2) mentang-mentang mahasiswa sedang berdemontrasi membuat macet jalanan, berantem dengan petugas dan lain-lain; (3) mentang-mentang kaya raya, apapun bisa dibeli termasuk kedudukan atau jabatan; (4) mentangmentang sudah menjadi pemimpin terpilih lalu lupa akan janji-janjinya selama berkampanye; (5) mentang-mentang miskin bisa saja kemudian bersikap ingin selalu dikasihani dan tidak mau berupaya; (6) mentang-mentang bodoh lalu mengatakan semua karena takdir; padahal jarang belajar dengan rajin; (7) mentang-mentang jadi pengemudi angkot atau raja jalanan seenaknya saja bebas menurunkan dan menaikkan penumpang di tengah jalan; (8) mentang-mentang penumpang seenaknya menyetop kendaraan disembarang tempat yang dapat mengganggu jalur lalu lintas; (9) mentangmentang tukang becak, seenaknya menerobos sana sisi tanpa memperhatikan rambu-rambu lalu lintas; (10) mentang-mentang jadi manajer seenaknya saja dia mengambil keputusan strategis tanpa membahasnya lebih dahulu dengan asisten manajer dan stafnya; (11) mentang-mentang punya kekuasaan, sang manajer memutuskan untuk mengusulkan pada direktur personalia agar beberapa karyawan yang tidak disenanginya segera dipecat; (12) mentang-mentang sering disebut sebagai aset perusahaan, para karyawan kerap menuntut diberi kesejahteraan tinggi tanpa melihat kondisi kesehatan perusahaan; (13) mentang-mentang sebagai komponen pembangunan, untuk masalah apapun lalu karyawan mengambil jalan pintas yakni dengan melakukan protes berbentuk mogok kerja; (14) mentang-mentang sering diberi kesempatan berpendapat maka ada karyawan yang suka menentang perintah manajer sebagai atasannya; (15) mentang-mentang senior dan atau tingkat pendidikannya lebih tinggi suka meremehkan rekan kerja lainnya; (16) Mentang-mentang orang tua, seenaknya bentak-bentak anaknya; (17) mentang-mentang anak seenaknya membangkang perintah orang tua.

Cara mengatasi sikap mentang mentang yaitu pertama, diajak untuk mengubah perilakunya lewat pendekatan personal. Kalau itu terjadi pada mahasiswa maka pembimbing, atau dosen atao mentor yang mengatasinya. Yang bersangkutan diminta melakukan evaluasi diri untuk menyadarkan diri bahwa perilaku mentang-mentang lebih banyak ruginya ketimbang manfaatnya. Kedua, yang bersangkutan secara alami merasakan adanya pertentangan dari lingkungan terhadap dirinya. Adanya tindakan isolasi dari rekan mahasiswa yang lain misalnya, itu sudah merupakan sanksi sosial yang 
harus diterimanya. Lambat laun timbul kesadaran dan mawas diri. Dan perubahan pun bakal terjadi. Yang tadinya bersikap mentang-mentang menjadi seseorang yang rendah hati dan bersahabat kepada teman mahasiswa yang lain. Ketiga, bentuk tengah, dari kedua cara sebelumnya yakni dengan senantiasa diingatkan dan diingatkan secara terus menerus agar mahasiswa yang mempunyai sikap mentang-mentang menyadari bahwa tindakannya itu tidak disukai oleh orang lain. Keberhasilan ketiga pendekatan itu akan lebih signifikan lagi apabila seluruh komponen civitas akademika selalu memberikan keteladanan kepemimpinan motivasi dan kepribadian menyenangkan atau tidak angkuh kepada para mahasiswanya. Para mahasiswa tanpa diminta cepat atau lambat akan menjauhi sikap mentang-mentang.

\section{SIMPULAN}

Setelah membahas mengenai Ojo Dumeh, maka kita dapat mengambil kesimpulan bahwa implementasi falsafah Ojo Dumeh dirasa sangat diperlukan pada jaman seperti sekarang ini karena Ojo Dumeh sebagai falsafah masih tetap relevan dan mempunyai nilai yang sangat luhur dan universal.yang diyakininya sangat bisa menjadikan hubungan antar sesama mahasiswa menjadi lebih baik. Ojo Dumeh mampu mengajak kita untuk menghargai orang-orang disekitar kita karena kita tinggal dan hidup bersama berdampingan satu dengan yang lain. Menganggap orang-orang disekitar kita adalah penting bagi kita karena kita adalah makhluk sosial, makhluk yang sama derajatnya di hadapan Tuhan. Ojo Dumeh memberikan kesadaran kepada kita bahwa hidup didunia ini hanya sementara bukan untuk selamanya. Kesadaran diri ini menciptakan sifat kehati-hatian, dengan selalu ingat bahwa ada orang disekitar kita atau ada orang yang secara sosial berada dibawah kita, dan memberikan isyarat bahwa kalau kita tidak berhati-hati maka kita bisa jatuh ke posisi tersebut. Ojo Dumeh menciptakan sifat kehati-hatian bukan menciptakan kekhawatiran atau sifat takut. Kita tidak berarti apa-apa tanpa adanya orang lain. Dengan tidak mentang-mentang berarti juga kita tidak overvalued. Bahwa dengan perilaku kita yang tidak mentang-mentang berarti kita memperlakukan orang lain secara lebih utuh (memanusiakan manusia yang sama derajatnya) dan membuat orang lain senang adalah bentuk ibadah, termasuk didalamnya adalah kita bisa mensyukuri apa yang ada pada diri kita sehingga kita tidak berprasangka negatif pada sesama yang akhirnya akan membuang energi kita. Dan kearifan untuk ojo dumeh inilah yang mengantar banyak orang menjadi sukses. Bahkan Ojo Dumeh dapat melipat gandakan kekuatan dan kelebihan kita sehingga kita lebih powerful. Untuk itulah maka kearifan jawa ini perlu untuk diimplementasikan dalam kehidupan sehari-hari.

\section{DAFTAR PUSTAKA}

Dhammasuubho, B. (2009). Perjalanan Sang Waktu. Tanpa Penerbit.

Mangkuprawira, S. (2009). Mengerem Sikap Mentang-Mentang. 9 January 2009 dari http://indosdm.com/mengerem-sikap-mentang-mentang

Rahardjo, M. (2010). Ojo Dumeh. Artikel, 03 April 2010, dari http://mudjiarahardjo.com/

Suprayogi, D. (2010). Ojo Dumeh, Ojo Kagetan, lan Ojo Gumunan. OPINI, 21 September 2010 dari http://sosbud.kompasiana.com

Walters, J. D. (2004). Seni Kepemimpinan. Jakarta: Dahara Prize. 